\title{
СРАВНИТЕЛЬНАЯ ОЦЕНКА КООРДИНАЦИОННЫХ ПОЛИЭДРОВ ГИДРОАЦЕТАТОВ ЩЕЛОЧНЫХ МЕТАЛЛОВ
}

\author{
Енделадзе Нарико Отаровна, доктор химических наук, профессор, Государственный \\ Университет Акакия Церетели. г. Кутаиси. Грузия. \\ Чиковани Манучар Илушович, доктор химических наук. профессор, Государственный \\ Университет Акакия Церетели. г. Кутаиси. Грузия. \\ Кахидзе Нино Анзорьиевна, доктор химических наук, профессор, Государственный \\ Университет Акакия Церетели. г. Кутаиси. Грузия \\ Чубинидзе Александр Давидович, доктор химических наук. профессор, Государственный \\ Университет Акакия Церетели. г. Кутаиси. Грузия
}

\section{DOI: https://doi.org/10.31435/rsglobal_conf/30052021/7579}

\begin{abstract}
It is investigated coordination polyhedrons of S-metal's hydroacetates. Crystal-chemical formulas of the corresponding compounds are: Lithium hydroacetates, Kalium, Rubidium and Cesium(2), $\mathrm{LiH}\left(\mathrm{CH}_{3} \mathrm{COO}\right)_{2}, \mathrm{KH}_{2}\left(\mathrm{CH}_{3} \mathrm{COO}\right)_{3}, \mathrm{RbH}\left(\mathrm{CH}_{3} \mathrm{COO}\right)_{2},(\mathrm{Cs}) \mathrm{H}\left(\mathrm{CH}_{3} \mathrm{COO}\right)_{2}$ and $\mathrm{Cs}_{3} \mathrm{H}_{5}\left(\mathrm{CH}_{3} \mathrm{COO}\right)_{8}$.

These substances as mono-crystals are obtained and synthesized by authors. Coordination number of metals is approximately (4-8) and are realized in the form of distorted polyhedrons - tetrahedron, prism, cube, seven-sided polygon.

Structural changes has been observed, when considering compounds with respect to growth of radii of metals. Namely, there are generated infinite columns or chains, created by polyhedrons of Oxygen atoms.

Among the structures which are mentioned above, noteworthy is dimmer $\mathrm{Li}_{2} \mathrm{O}_{6}$, formed by Oxigencontaining tetrahedrons with the centre at the Lithium atoms, which are contained in chains.
\end{abstract}

Keywords: hydroacetate, polyhedron, dimmer, coordination, bond.

Введение. Синтез и исследование гидроформиатов и гидроацетатов щелочных и щелочноземельных элементов проводятся многими исследователями с начала прошлого столетия. Интерес к изучению кислых солей карбоновых кислот особенно возрос за последние четыре десятилетия. В этих соединениях водородные связи, играют существенную роль при формировании структур кислых солей.

Основная причина малой изученности этих соединений, так называемых кислых солей это их крайняя неустойчивость при обычных условиях. Большинство из гидроацетатов и гидроформиатов чрезвычайно быстро разлагаются на воздухе с выделением соответствующей кислоты и без предварительной эвакуации кристаллов, они не могут быть изучены в структурном плане.

Актуальность изучения строения этих соединений определяется не только наличием в них сильных водородных связей, но и важными в практическом плане свойствами. Имеются данные о том, что кристаллы ацетатов и формиатов щелочных элементов обладают в некоторых случаях ацентричными структурами и являются в этом плане перспективными соединениями, которые могут найти применение как пьезоэлектрики и сегнетоэлектрики, либо как материалы с нелинейными оптическими свойствами.

Цель. Изучение строения кислородных координационных полиэдров гидроацетатов.

Методы исследования. Ниже приведены кристаллохимические формулы гидросоединений некоторых щелочных металлов в частности: $\mathrm{LiH}\left(\mathrm{CH}_{3} \mathrm{COO}\right)_{2} ; \mathrm{KH}_{2}\left(\mathrm{CH}_{3} \mathrm{COO}\right)_{3}$; $\mathrm{RbH}\left(\mathrm{CH}_{3} \mathrm{COO}\right)_{2} ; \mathrm{CsH}\left(\mathrm{CH}_{3} \mathrm{COO}\right)_{2} ; \mathrm{Cs}_{3} \mathrm{H}_{5}\left(\mathrm{CH}_{3} \mathrm{COO}\right)_{8}$.

Вышеупомянутые соединения были синтезированы нами.

Монокристаллы гидроацетатов были выделены изотермическим испарением при комнатной температуре, сравнительно невысокой, $(\leq 20 \%$ масс) концентрации раствора средней соли в ледяной уксусной кислоте.

Сьёмка кристаллов проводилась в эвакуированных пирексовых капилярах под слоем маточного раствора на автоматическом дифрахтометре CAD-4-SDP. Bce вычисления проводились на мини ЭВМ РДР 11/55 t по комплексу програм ENX SDP [1]. 
Результаты исследования. В структурах соединений лития структурная единица - это сдвоенные по ребрам димеры двух кислородных тетраэдров атомов лития $\mathrm{Li}_{2} \mathrm{O}_{6}$, которые в случае дигидрата ацетата лития связаны в двумерные цепи ацетатными группами, а отдельные цепи - водородными связями молекул воды в трёхмерную постройку. В структуре же гидроацетата лития, аналогичные сдвоения кислородные тетраэдры атомов лития - связанные в цепи депротонированными ацетатными группировками, дополнительно координируются протонированной ацетатной группой и таким образом образуется гидрофобная зигзагообразная цепочка (рис.1)

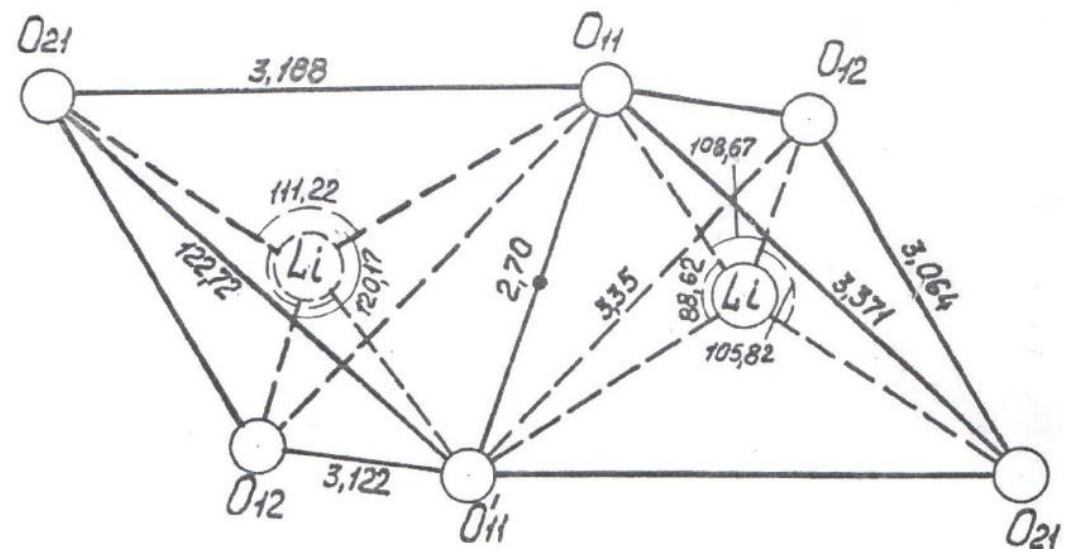

Pис.1. Димиризованная группа $\mathrm{Li}_{2} \mathrm{O}_{6}$ в структуре $\mathrm{LiH}\left(\mathrm{CH}_{3} \mathrm{COO}\right)_{2}$

Тетраэдры $\mathrm{LiO}_{4}$ сильно искажены видимо за счёт объединения по общему ребру в димеризованную группу $\mathrm{Li}_{2} \mathrm{O}_{6}$ Среднее расстояние $(1,926 \AA) \mathrm{Li}-\mathrm{O}$ в тетраэдре имеет „обычный“ характер. Расстояния в карбоксильных группах показывают, что димер состоит из молекулы уксусной кислоты и депротонированной ацетатной группы.

На рис.2 приведён кислородный полиэдр атома калия в структуре $\mathrm{K}\left[\mathrm{H}_{2}\left(\mathrm{CH}_{3} \mathrm{COO}\right)_{3}\right]$. Представляющий собой искаженную квадратную антипризму (к.ч. 8). Полиэдры атомов калия контактируются друг с другом по ребрам $\mathrm{O}(21)-\mathrm{O}(12)$ и $\mathrm{O}(11)$ и $\mathrm{O}(31)$, образуя зигзагообразные слои, распространяющиеся параллельно плоскости (хуо).

B структуре тримеры образуют дискретные группировки $\left[\mathrm{H}_{2}\left(\mathrm{CH}_{3} \mathrm{COO}\right)_{3}\right]^{-}$. Следует отметить, что контакт $\mathrm{O}(12)-\mathrm{H}(1) \ldots . \mathrm{O}(21)$ является одновременно ребром полиэдра $\mathrm{KO}_{8}$, с чем, видимо, связано искажение этого полиэдра. Близкий по строению тример образуется в структуре соединения $\mathrm{Cs}_{3}\left[\mathrm{H}_{5}\left(\mathrm{CH}_{3} \mathrm{COO}\right)_{8}\right]$.

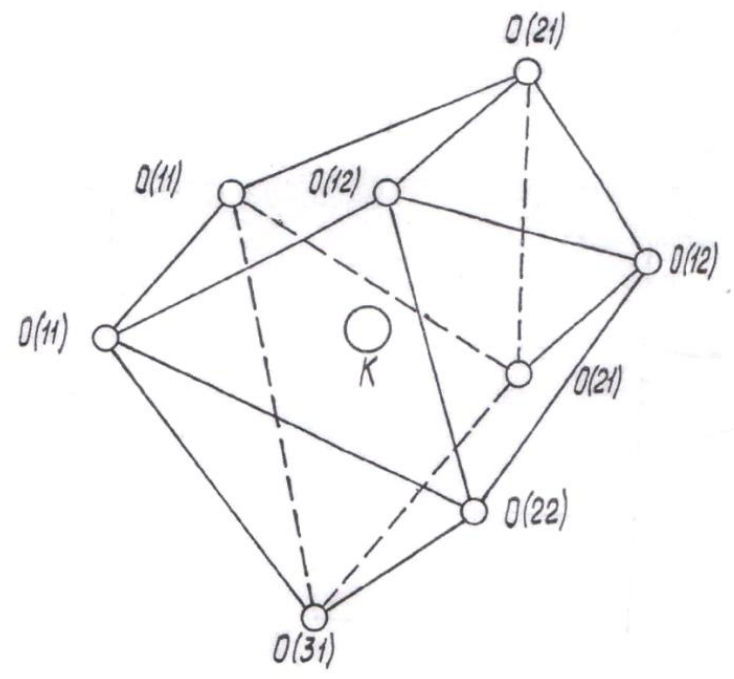

Puс.2. полиэдр $\mathrm{KO}_{8}$ в структуре $\mathrm{KH}_{2}\left(\mathrm{CH}_{3} \mathrm{COO}\right)_{3}$

Среднее расстояние $<\mathrm{K}-\mathrm{O}>2,864(3)$ соответствует сумме ионных радиусов $\mathrm{O}^{2}$ и катиона калия для координационного числа 8 по Шеннону [2]. 
Исследована и изучена кристаллическая структура двух сольватов ацетата калия, которые представляют большой научный интерес [3].

$\mathrm{B}$ структуре $\mathrm{RbH}\left(\mathrm{CH}_{3} \mathrm{COO}_{2}\right)$ атомы $\mathrm{Rb}$ занимающие две независимые позиции, координированы атомами димеров по мотиву ромбоэдрически искаженного куба $\mathrm{Rb}(1) \mathrm{O}_{8}$ (рис.3) и неправильного семивершинника $\mathrm{Rb}(2) \mathrm{O}_{7}$. Контакты Ас-групп с катионом монодентатные. Средние расстояния $\mathrm{Rb}-\mathrm{O}$ в полиэдрах $(3,05$ и $2,80 \AA)$ близки аналогичным расстояниям, найденным в структурах $\mathrm{RbH}\left(\mathrm{C}_{9} \mathrm{H}_{9} \mathrm{O}_{3}\right)_{2}$ [4], $\mathrm{RbH}\left(\mathrm{C}_{2} \mathrm{H}_{3} \mathrm{O}_{3}\right)_{2}$ [5].

Полиэдры рубидия сочленены общими треугольными гранями и ребрами в колонки, распространяющиеся вдоль (010). Колонки полиэдров объединяются в каркас посредством ацетатных димеров.

Ocобое строение имеет соединение $\mathrm{CsH}(\mathrm{Ac})_{2}$, в котором атом Cs представлен как координационный многогранник $\mathrm{CsO}_{8}$ - искажённая антипризма. В данном этапе детальное изучение полиэдра не проводилось.

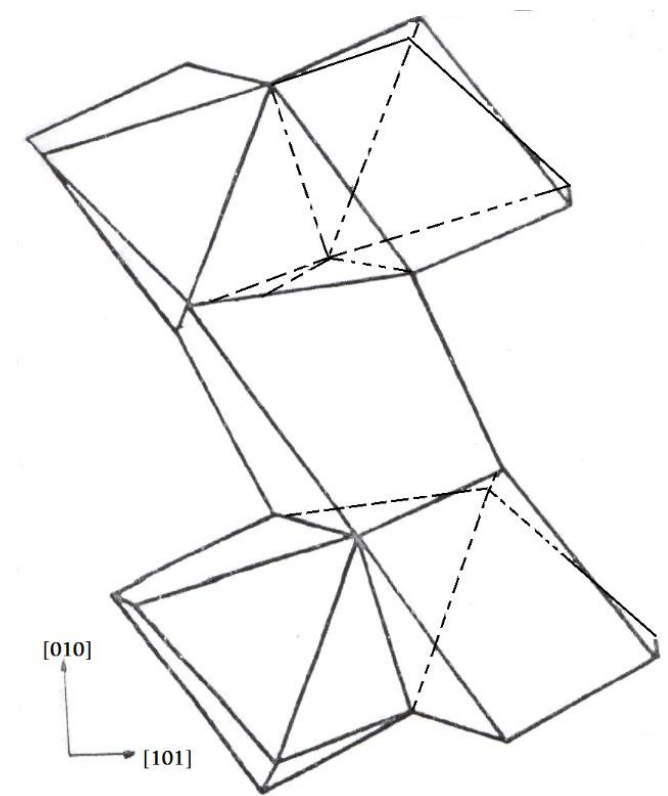

Рuc.3. Колонка полиэдров $R b(2) O_{7}$ и $R b(1) O_{8}$ (в центре инверсии)

$\mathrm{B}$ структуре $\mathrm{Cs}_{3} \mathrm{H}_{5}\left(\mathrm{CH}_{3} \mathrm{COO}\right)_{8}$ гидроацетат цезия имеет два сорта атомов металла $\mathrm{Cs}(1)$ и $\operatorname{Cs}(2)-$ координированы атомами кислорода семи сортов (рис.4).

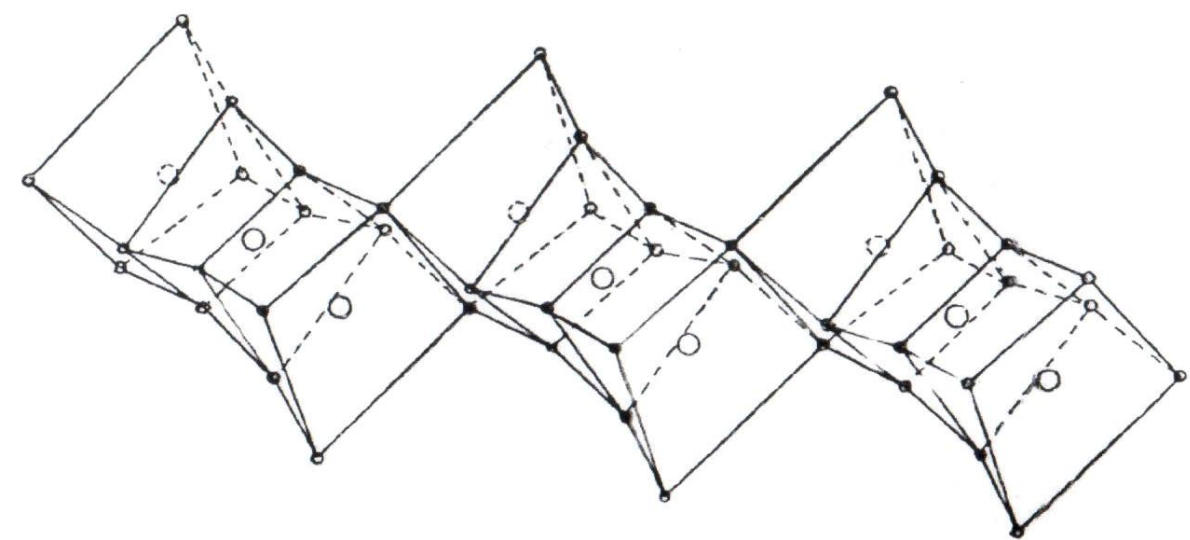

Puс.4. Проекция полиэдров $\mathrm{Cs}_{8}$ вдоль [010] в структуре $\mathrm{Cs}_{3}\left[\mathrm{H}_{5}\left(\mathrm{CH}_{3} \mathrm{COO}\right)_{8}\right]$

$\operatorname{Cs}(1)$ окружен восьмью атомами кислорода по мотиву искаженного ромбоэдра. Четырехугольники оснований образованы атомами $\mathrm{O}(11), \mathrm{O}(22), \mathrm{O}(31), \mathrm{O}(41)$ их отклонением от плоскостей основании $0,18 \AA$. Атом $\operatorname{Cs}(2)$ находящийся в общем положении, координирован также по восьмивершиннику (искаженный ромбоэдр). 
Для сравнительной оценки координационных полиэдров гидроацетатов щелочных металлов была использована таблица отнесения структур полиэдров различных типов (таб1).

Координационные полиэдры атомов цезия сочленены тремя общими четырёхугольными гранями. В свою очередь, тройки полиэдров связаны общими ребрами в цепи (рис.4).

Цепи контактируют друг с другом посредством ацетатных димеров. Средние расстояния Cs-O практически одинаковы в обоих полиэдрах $(3,08)$ и $(3,21) \AA$ и близки аналогичным расстояниям, найденным в структуре $\mathrm{CsH}_{5}\left(\mathrm{PO}_{4}\right)_{2}$ [6].

Выводы. В качестве выводов целесообразно отметить, что по способу объедения кислородных полиэдров атомов метала и выделения отдельных элементов, образующих структуру, практически все соединения (как средние, так и „кислые“ соли) можно объединить в следующие группы.

Соединения лития (двухводный средний ацетат и гидроацетат), которые ввиду особых кристаллохимических свойств относят к особым, в общем ряду рассматриваемых структур, образуют димеры $\mathrm{Li}_{2} \mathrm{O}_{6}$ из кислородных тетраэдров атомов лития, которые посредством ацетатных группировок связаны в цепи.

Следующая группа соединений - это слои, имеющие в основе свой структуры двумерные образования (слой или „стенки“) из соседних по ребрам и вершинам кислородных в полиэдров щелочных и щелочноземельных металлов, распространяющиеся бесконечно в двух измерениях. К этой общей группе соединений относятся как средние так и кислые соли.

Третья группа соединений - это соединения, в которых образуются гидрофобные колонки, бесконечные в одном направлении с метильными группами, направленными во „внеколоночное“ пространство. Отдельные колонки связаны ван-дер-вальсовым взаимодействием.

Таблица 1. Отнесение структур полиэдров к различным типам

\begin{tabular}{|c|c|c|c|c|}
\hline соединение & Тип структуры & $\begin{array}{c}\text { Тип димера или } \\
\text { примера }\end{array}$ & $\begin{array}{l}\text { Тип полэдра } \\
\text { атом в металле } \\
\text { и к.ч. }\end{array}$ & Упаковка полиэдров \\
\hline $\mathrm{LiAc} \cdot 2 \mathrm{H}_{2} \mathrm{O}$ & цепочный & - & Тетраэдр к.ч.- 4 & $\begin{array}{l}\text { Тетраэдры связаны по ребру в } \\
\text { димер }\end{array}$ \\
\hline $\mathrm{LiH}(\mathrm{Ac})_{2}$ & цепочный & ассиметричный & Тетраэдр к.ч.- 4 & $\begin{array}{l}\text { Тетраэдры связаны по ребру в } \\
\text { димер }\end{array}$ \\
\hline $\mathrm{NaAc}$ & $\begin{array}{l}\text { Слои, параллельные } \\
\text { группы направлены в } \\
\text { межслоевое } \\
\text { пространство } \\
\end{array}$ & ассиметричный & $\begin{array}{l}\text { Искаженная } \\
\text { тригональная } \\
\text { призма к.ч. - } 6\end{array}$ & $\begin{array}{l}\text { Зигзагообразные цепи, связанных } \\
\text { по ребрам призм } \mathrm{NaO}_{6}, \\
\text { образующих слои, параллельные } \\
\text { (хуо) }\end{array}$ \\
\hline $\mathrm{NaH}(\mathrm{Ac})_{2}$ & каркасная & симметричный & $\begin{array}{l}\text { Октоэдр } \\
\left(\mathrm{Na} 2 \mathrm{O}_{6}\right) \\
\text { тригональная } \\
\text { призма }\left(\mathrm{Na}_{6}\right) \text {, } \\
\text { к.ч. - } 6\end{array}$ & $\begin{array}{l}\text { Тройные блоки из одной } \\
\text { тригональной призмы и двух } \\
\text { симметрических октаэдров, } \\
\text { направленные вдоль оси третьего } \\
\text { порядка (диагональ куба) }\end{array}$ \\
\hline $\mathrm{NaH}_{2}(\mathrm{Ac})_{3}$ & $\begin{array}{l}\text { Блочный с } \\
\text { гидрофобными } \\
\text { колонками-блоками } \\
\end{array}$ & $\begin{array}{l}\text { тримери } \\
\text { асимметричные }\end{array}$ & $\begin{array}{l}\text { Тригогальная } \\
\text { антипризма к.ч. } \\
6\end{array}$ & $\begin{array}{l}\text { Винтовые цепи (вдоль оси 4 }) \\
\text { объединенных по ребрам } \\
\text { полиэдров }\end{array}$ \\
\hline $\mathrm{KH}(\mathrm{Ac})_{2}$ & $\begin{array}{l}\text { Гидрофобные } \\
\text { колонки, отдельные } \\
\text { колонки связаны ван- } \\
\text { дер-ваальсовыми } \\
\text { силами } \\
\end{array}$ & $\begin{array}{l}\text { Димери атомов не } \\
\text { определены, } \\
\text { ассиметричный? }\end{array}$ & $\begin{array}{l}\text { к.ч.7 } \\
\text { комбинация } \\
\text { полуоктаэдра и } \\
\text { тригональной } \\
\text { призмы } \\
\end{array}$ & $\begin{array}{l}\text { Полиэдры } \mathrm{KO}_{7} \text { связаны по ребрам } \\
\text { в зигзагообразные цепи }\end{array}$ \\
\hline $\mathrm{KH}_{2}(\mathrm{Ac})_{3}$ & Слоистый & $\begin{array}{l}\text { тример } \\
\text { асимметричный }\end{array}$ & Додекаедр к.ч.8 & Додекаедр $\mathrm{KO}_{8}$ \\
\hline $\mathrm{Rb}_{2} \mathrm{H}_{2}(\mathrm{Ac})_{3}$ & $\begin{array}{l}\text { Каркасный слой } \\
\text { связанный группами } \\
\text { AcIII в каркас }\end{array}$ & $\begin{array}{l}\text { Два асимметричных } \\
\text { димера }\end{array}$ & $\begin{array}{l}\text { Куб и } \\
\text { семивершинник } \\
\text { (к.ч.8 и 7) }\end{array}$ & $\begin{array}{l}\text { Полиэдры } \mathrm{Rb}_{10} \text { и } \mathrm{Rb} 2 \mathrm{O}_{7} \\
\text { объединении гранями и } \\
\text { вершинами в слой (стенки) } \\
\text { связанные группами Ас } \\
\end{array}$ \\
\hline $\mathrm{CsH}(\mathrm{Ac})_{2}$ & $\begin{array}{l}\text { Трехмерный каркас } \\
\text { из связанных } \\
\text { Ас. группами цепей }\end{array}$ & $\begin{array}{l}\text { Центросимметричный } \\
\text { димер }\end{array}$ & $\begin{array}{l}\text { Искаженная } \\
\text { антипризм к.ч.8 }\end{array}$ & $\begin{array}{l}\text { Полиэдры связаны ребрами в } \\
\text { зигзагообразные цепы, } \\
\text { направленные вдоль /001/ }\end{array}$ \\
\hline $\mathrm{Cs}_{2} \mathrm{H}_{3}(\mathrm{Ac})_{4}$ & $\begin{array}{l}\text { Слоистая, } \\
\text { параллельные /101/ }\end{array}$ & $\begin{array}{l}\text { Центросимметричный } \\
\text { димер, тример }\end{array}$ & $\begin{array}{l}\text { Искаженная } \\
\text { тетрагональная } \\
\text { призма к.ч.8 }\end{array}$ & $\begin{array}{l}\text { Блоки из трех призм } \mathrm{CsO}_{8} \text { (грани) } \\
\text { связаны по ребрам в колонки, } \\
\text { вдоль } / 110 /\end{array}$ \\
\hline
\end{tabular}




\section{ЛИТЕРАТУРА}

1. Frenz B. A. The enraf - nonius CAD-4-SDP-A real-time system ror concurrent X-ray collection and crystal //structure determination// In: Computing in Crystallography - Holland: Delft. U. P. 1978,- P260.

2. Shannon R. D. Nevised effective ionic radii and systematic studies of interatomic distances in halides and chalcogenides. //Ibid. - 1976. - v. A36. - p. 751-753.

3. Кристаллические структуры двух сольватов (18-краун-6) ацетата калия. П. Liebing, A. Zaeni, Ф. Олбрих и FT Эдельман Acta Cryst. (2016). E 72, 1757-1761 https://doi.org/10.1107/S2056989016017436

4. Moore P. B., Pluth J. J., Molin-Morris J. A., Weinstein D.A. The crystal structures of rubidium and sodium acid salts of -methoxy - phenylacetic acid - Acta Cryst., 1980, V. B. 36. \#1. P. 47-50.

5. Golic L., Speakman J.C. The crystal structures os rubidium hydrogen bisglycollate - J. chem. Sos. 1965. P. 2521-2525

6. Ефремов В.А., Трунов В.К., Мацичек И., Гудиница Э.Н., Факеев В.А. О неравноценности Н атомов в кристаллах $\mathrm{Cs}\left[\mathrm{H}_{5}\left(\mathrm{PO}_{4}\right)_{2}\right]$ - Ж.неорг. Хим., 1981, т. 26, Вып.12, С. 3213-3217. 